\title{
Optimized cultivar deployment improves the efficiency and sta- bility of sunflower crop production at national scale.
}

Pierre Casadebaig (1)*, Arnaud Gauffreteau (2), Amélia Landré (1), Nicolas B. Langlade (5), Emmanuelle Mestries (4), Julien Sarron (1, 6), Ronan Trépos (3), Patrick Vincourt (5), Philippe Debaeke (1)

(1) Université de Toulouse, INRAE, UMR AGIR, F-31320, Castanet-Tolosan, France

(2) Université Paris-Saclay, INRAE, AgroParisTech, UMR Agronomie, F-78850, Thiverval-Grignon, France

(3) Université de Toulouse, INRAE, UR MIAT, F-31320, Castanet-Tolosan, France

(4) Terres Inovia, F-31320, Castanet-Tolosan, France

(5) Université de Toulouse, INRAE, UMR LIPM, F-31320, Castanet-Tolosan, France

(6) Université de Montpellier, CIRAD, UPR HortSys, F-34398 Montpellier, France

(*) Corresponding author

\begin{abstract}
Plant breeding programs design new crop cultivars which, while developed for distinct populations of environments, are nevertheless grown over large areas during their careers. Over its cultivation area, the crop is exposed to highly diverse stress patterns caused by climatic uncertainty and multiple management options, which often leads to decreased expected crop performance.

In this study, we aim is to assess how finer spatial management of genetic resources could reduce the genotype-phenotype mismatch in cropping environments and ultimately improve the efficiency and stability of crop production. We used modeling and simulation to predict the crop performance resulting from the interaction between cultivar growth and development, climate and soil conditions, and management practices. We designed a computational experiment that evaluated the performance of a collection of commercial sunflower cultivars in a realistic population of cropping conditions in France, built from extensive agricultural surveys. Distinct farming locations that shared similar simulated abiotic stress patterns were clustered together to specify environment types. Optimization methods were then used to search for cultivars $\times$ environments combinations that lead to increased yield expectations.

Results showed that a single cultivar choice adapted to the most frequent environment-type in the population is a robust strategy. However, the relevance of cultivar recommendations to specific locations was gradually increasing with the knowledge of pedo-climatic conditions. We argue that this approach while being operational on current genetic material could act synergistically with plant breeding as more diverse material could enable access to cultivars with distinctive traits, more adapted to specific conditions.
\end{abstract}




\section{Introduction}

\section{Context}

The use of fertilizers, irrigation, and pesticides mitigated the effects of climatic hazards and had a large and positive impact on crop yield gains between 1960 and 2000 (Tilman et al., 2002; Foley et al., 2005 ). Currently, because of the simultaneous need to reduce inputs in agricultural systems, and the climatic uncertainty caused by climate change, the variability of cropping conditions increased as compared to late century conditions. Over its global cultivation area, a crop is thus exposed to highly diverse biotic and abiotic stress patterns, which can often lead to decreased crop performance regarding the expected level and cause yield gap. Reducing these yield gaps could be achieved by two conflicting strategies: increase inputs or increase the crop resource-use efficiency (Sadras and Denison, 2016).

Plant breeding is a key asset to increase crop resource use efficiency by designing new cultivars adapted to distinct populations of environments (e.g. Voss-Fels et al., 2019 for wheat; Vear et al., 2003 for sunflower). Cultivars are nevertheless grown over large areas during their careers, which can encompass locations and management practices for which the cultivars were not designed for. In continental Europe, sunflower is mostly cultivated in eastern and southern regions (18.7 M hectares in 2018). In 2018, Russian Federation, Ukraine (together 49\%, $26.9 \mathrm{Mt}$ ), and UE-28 (18\%, $9.9 \mathrm{Mt}$ ) were the largest sunflower grain producers in the world accounting for $68 \%$ of global volume (FAO, 2020). In the last 30 years, the production area for the sunflower crop surged in Central and Eastern Europe (Ukraine, Russian Federation, + 9.6 M hectares together) while it decreased in Western Europe (France, Spain, - 1.1 M hectares together) (FAO, 2020). These changes in global acreage, while accounted for in plant breeding programs can lead to sub-optimal use of the developed genetic resources.

Phenotypic plasticity is defined as the range of phenotypes a single genotype can express as a function of its environment (Nicotra et al., 2010). At the population level, this process underlies the relative variation in performance of cultivars across environments. It is commonly referred as genotype $\times$ environment interactions in plant breeding and agricultural extension (Van Eeuwijk et al., 2016), which can outweigh main genotype effect and can explain up to $20 \%$ of total yield variance observed in multi-environment trials (e.g. Foucteau et al., 2001, for sunflower). Consequently, yield gap reduction is limited by our ability to identify favorable combinations of cultivars and cropping conditions, given the resources available to experiment among possible combinations in the target population of environments (Comstock, 1976; Hammer and Jordan, 2007). Crop improvement can be viewed as a search strategy on a genotypeenvironment space (Hammer et al., 2006) to manage the genetic and environmental resources more efficiently by taking advantage of phenotypic plasticity.

Plant modeling approaches have emerged as a method to complement and improve the resource-limited experimental exploration of the adaptation landscape (Chapman et al., 2003; Messina et al., 2006, 2011; Hammer et al., 2006). Such models represent biological processes linked to plant growth and development as a function of time, environment (climate, soil, and management), and genetic diversity. Crop simulation models have the capacity to explore consequences of potential agronomic and breeding interventions in the design of crops for production systems (Sinclair et al., 2019; Hammer et al., 2019) and have been successfully used in a number of cases (see Chenu et al., 2017 for a review in wheat).

Two cases are particularly relevant to leverage phenotypic plasticity and support cultivar deployment strategies. The first one, referred as environmental characterization or envirotyping (see $\mathrm{Xu}, 2016$ for a review), aims to analyze environmental impacts on crop and produce a set of categories (environmenttypes) grouping multiple cropping conditions (e.g. distinct locations and years) into comparable stress scenarios. While climate, soil, and management data could directly be used as classifiers, simulation was successfully used to generate new variables representing abiotic stress per se by accounting for the interactions between the plants and their environments (Chenu et al., 2013), potentially more informative than raw environmental data (Mangin et al., 2017). These variables, such as time series of water supply:demand ratio, can then be clustered into distinct stress scenarios over a large spatial and temporal scale (Chenu et al., 2013; Gosseau et al., 2019). In the second case, crop models are at the core of numerical experiments, aiming to complement and extend field experiments such as multi-environment trials (MET). The capacity to sample the target population of environments for a set of cultivars along with the possibility to formalize optimization problems enabled applications in cultivar selection (e.g. Li et al., 2013), trait evaluation in multiple environment types (Chapman et al., 2002), or trait optimization 
bioRxiv preprint doi: https://doi.org/10.1101/2020.09.21.306076; this version posted September 22, 2020. The copyright holder for this preprint (which was not certified by peer review) is the author/funder, who has granted bioRxiv a license to display the preprint in perpetuity. It is made available under aCC-BY 4.0 International license.

for performance or resistance criteria (Semenov and Stratonovitch, 2013; Paleari et al., 2015; Picheny et al., 2017a).

\section{Problem and aim}

In France, the commercial sunflower cultivars are a subset of those developed for the European market, while the French cropping conditions does not necessarily reflect those for which European cultivars were developed for (Debaeke et al., 2017; Gosseau et al., 2019). In this study, our aim is to assess how finer spatial management of available genetic resources could reduce the genotype-phenotype mismatch in actual cropping conditions and ultimately improve the efficiency and stability of crop production.

For that we developed an approach (outlined in Figure 1) where we used postal surveys to describe the cultivation area and crop management practices at the farm scale, over the national acreage. We then designed a realistic numerical experiment based on these informations, as a factorial combination of distinct farm locations (including crop management) and a collection of commercial cultivars. Highresolution climate and soil gridded datasets were used to complete survey data and enhance climatic coverage. Simulation allowed to predict the crop performance resulting from the interaction between cultivar growth and development, climate and soil conditions, and management practices. Finally, we defined and solved optimization problems to assess different cultivar deployment strategies leading to increased yield expectations.

\section{Material and methods}

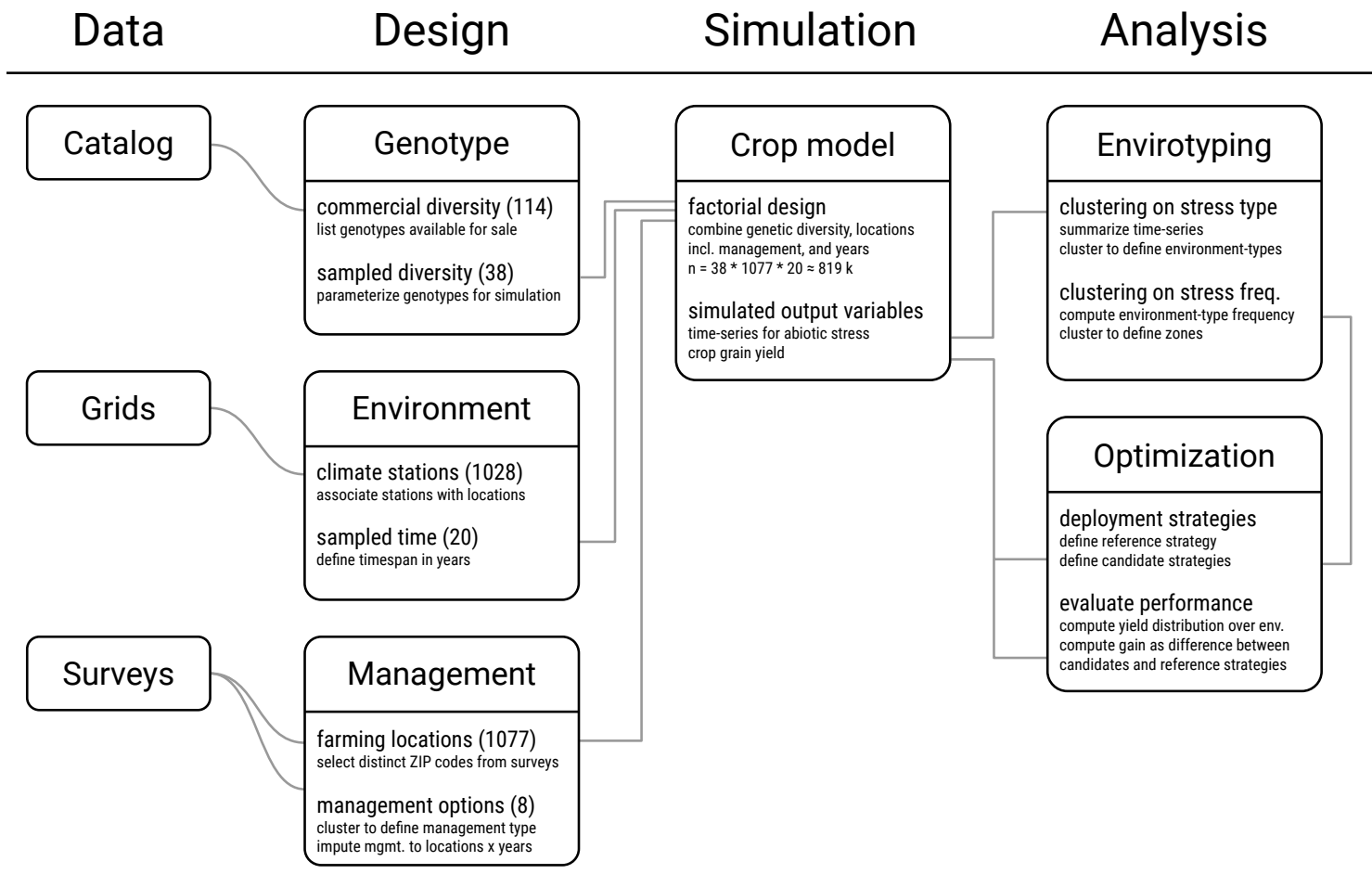

Figure 1. Outline of the approach used to compare cultivar deployment strategies. A synthetic view of the design, simulation, and analysis steps (columns). In the design step, each box presents the number of modalities used for genotype, locations, climate, and management factors along with a summary of the method used. In the simulation step, the box summarizes the design of the numerical experiment along with simulated variables. The analysis step illustrates how the envirotyping and optimization methods are linked together and how yield gains are computed. 


\section{Farm data}

Farming data concerning the sunflower crop in France were collected from extensive postal surveys conducted by an agricultural extension institute (Terres Inovia). Between 1997 and 2013, 11 years of data were gathered, representing 11969 farming situations in total (from 1077 distinct locations). In total, 14 crop management variables related to the sunflower crop were collected, including qualitative (e.g. cultivar, fungicide application, soil depth class) and quantitative variables (e.g. sowing date and density, nitrogen fertilization amount). We focused the study on variables linked to abiotic stress (water, radiation, temperature, nitrogen).

\section{Description of farming locations}

The farm data featured the ZIP code, which was used as an approximation of the actual farm geographical location (not collected).

We used the European Soil Database derived data (Hiederer, 2013, http://esdac.jrc.ec.europa.eu/content /esdb-derived-data, $1 \times 1 \mathrm{~km}$ grid cells) to obtain the quantitative soil properties corresponding to each location, i.e. total available water content, soil depth available to roots, bulk density, coarse fragments for two soil layers $([0,30 \mathrm{~cm}]] ,30 \mathrm{~cm}$, rooting depth]).

A 20 year period (1994-2013) of climatic data was obtained from the French national center for meteorological research $(\mathrm{CNRM})$, using a $8 \times 8 \mathrm{~km}$ grid dataset based on the interpolation of observed climatic data (Quintana-Segui et al., 2008, Meteo-France SAFRAN). Farm locations were associated with the closest climate grid point. Five climatic variables were used: minimal and maximal temperature $\left({ }^{\circ} \mathrm{C}\right)$, evapotranspiration $(\mathrm{mm})$, global radiation $\left(\mathrm{MJ} \mathrm{m}^{-2}\right)$, and precipitation $(\mathrm{mm})$.

\section{Cluster analysis of management practices}

In order to reduce the number of modalities in surveyed management practices, we used a classification analysis to cluster farming situations that shared similar management practices. First, a factor analysis for mixed data (FAMD, Pagès, 2004) was performed on the data to simplify variables that are correlated. We then performed a hierarchical cluster analysis (HCA, Kaufman and Rousseeuw, 2009) on the variables resulting from FAMD to cluster management practices.

\section{Crop modeling and simulation}

\section{Model description}

We used crop modeling and simulation to predict the grain yield in non-observed field environments. SUNFLO is a process-based simulation model for sunflower that was developed to simulate grain yield and oil concentration as a function of time, environment (soil and climate), management practices, and genetic diversity (Casadebaig et al., 2011; Lecoeur et al., 2011). Predictions with the model are restricted to potential or attainable yield (Van Ittersum and Rabbinge, 1997): only the main limiting abiotic factors (temperature, radiation, water, and nitrogen) are included in the algorithm. Weeds, pests, and diseases are therefore not accounted for in this study. The model simulates the main soil and plant functions: root growth, soil water and nitrogen dynamics, plant transpiration and nitrogen uptake, leaf expansion and senescence, and biomass accumulation. Four climatic variables are used as daily inputs for simulation:

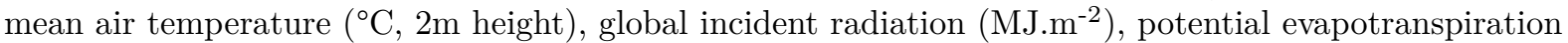
$(\mathrm{mm}$, Penman-Monteith) and precipitation $(\mathrm{mm})$. Soil properties are defined by its texture, maximum depth and daily nitrogen mineralization potential, while initial soil conditions are defined by residual mineral nitrogen and initial water content. The needed management practices include sowing date and density, irrigation and nitrogen fertilization (timing and amount). Globally, the SUNFLO crop model has about 50 equations and 64 parameters split into 33 species-dependent, 10 genotype-dependent, and 21 environment-related parameters. A report that summarizes the equations and parameters used in the model is available as supplementary information in Picheny et al. (2017a). 
bioRxiv preprint doi: https://doi.org/10.1101/2020.09.21.306076; this version posted September 22, 2020. The copyright holder for this preprint (which was not certified by peer review) is the author/funder, who has granted bioRxiv a license to display the preprint in perpetuity. It is made available under aCC-BY 4.0 International license.

SUNFLO was evaluated both on specific research trials (40 trials, 110 cultivar $\times$ environment combinations) and on agricultural extension trials that were representative of its targeted use (96 trials, 888 cultivar $\times$ environment combinations). Over these two datasets, the model was able to simulate significant $\mathrm{G} \times \mathrm{E}$ interactions and rank genotypes (Casadebaig et al., 2011, 2016). From these evaluations, we considered that SUNFLO was accurate enough to support optimization methods, i.e. allows discrimination between two given cultivars.

\section{Experimental design and numerical experimentation.}

To describe a realistic target population of environments for sunflower cropping in France, we used a factorial design crossing a cultivar list of commercial sunflower hybrids $(g=38)$, the surveyed farming locations (soil and crop management, $e=1077$ ) and 20 years of historical climate data $(1994-2013, t=20)$. The resulting design represented 818520 virtual fields $(n=g \times e \times t)$.

Genetic diversity was represented with $g=38$ cultivars resulting from the intersection of the list of cultivars actually available for sale in $2017(\mathrm{n}=125$, Terres Inovia, 2017) and those whose morphological and physiological characteristics were assessed for simulation $(n=69)$. Such characteristics were necessary to simulate genotype $\times$ environment interaction with the SUNFLO crop model, which uses measured phenotypic traits as genotype-dependent parameters. The estimation of these parameters is based on plant phenotyping, with methodology and protocols fully described for field (Casadebaig et al., 2011, 2016) and controlled conditions (Casadebaig et al., 2008; Gosseau et al., 2019).

Surveyed management practices were depicted with eight management systems resulting from the cluster analysis. These management systems were used for the simulation analysis, and qualified by the sowing date, plant density, and the amount of mineral nitrogen applied. (modalities indicated in Table 2). As some farms with different management systems shared the same postal code, the most frequent management system for each location-year combination was selected to assign a single management system to each location-year combination. Because the surveys were not conducted every years, the management systems missing from the factorial design were imputed assuming that management on the location did not change until the next surveyed date (last observation carried forward, LOCF).

For each genotype $\mathrm{x}$ location $\mathrm{x}$ year combination, five output variables were simulated by the SUNFLO crop model: seed yield at harvest, and four time-series corresponding to the impact of abiotic stressors on crop photosynthesis, i.e. heat stress as a function of mean air temperature, cold stress as a function of mean air temperature, water stress as a function of water deficit (simulated with the fraction of transpirable soil water, FTSW) and nitrogen stress as a function of nitrogen deficit (simulated by the nitrogen nutrition index, NNI, Debaeke et al., 2012).

Only in a few cases, the SUNFLO crop model failed to simulate seed production $(\sim 4.5 \%$ of genotype $\mathrm{x}$ environment combinations) either because of excessive water deficit or the predicted maturity date was too late in the season for a realistic harvest date. One cultivar was discarded from the analysis because simulated yield value were outliers in all environments. The difference between modalities in studied factors (locations, genotypes) for each step of the study is reported in Table 1.

\begin{tabular}{lrrrrr}
\hline level & location & station & year & genotype & environment \\
\hline survey & 1077 & 1028 & 11 & & 4574 \\
design & 1077 & 1028 & 20 & 38 & 21540 \\
simulation & 1075 & 1026 & 20 & 37 & 20566 \\
\hline
\end{tabular}

Table 1. Sampled cropping conditions at the survey, numerical design, and simulation levels. The modalities of the sampled factors are reported at different steps of the study: postal survey, numerical design of experiments, and actual simulated results. Columns correspond to the number of distinct farm geographical locations (location), the distinct grid points used as climate data source (station), the distinct climatic years and genotypes (survey data did not include the genotype name, only the maturity group), and environments defined as the distinct combinations of locations and years. 


\section{Clustering of environments.}

Each cropping condition (location-year combination), referred as environment, was characterized by four indices that were computed by integrating the simulated time series of abiotic stressors $\left(X_{e}\right)$ over the crop cycle ( $d$ days between sowing and harvest) and averaging for genetic diversity ( $g$ genotypes) (equation 1$)$.

$$
S_{e}=\frac{1}{n} \sum_{g=1}^{n} \sum_{t=1}^{d} 1-X_{e}
$$

with $S_{e}$, level of abiotic stressor $e$, i.e. for cold (LTRUE), heat (HTRUE), water (WRUE) or nitrogen (NRUE) stress. $X_{e}$, corresponding time series of the simulated impact of abiotic stressors on crop photosynthesis.

We then proceeded with two successive hierarchical cluster analysis, based on Euclidian distances and Ward's variance clustering method. The final cluster number was defined according to the between:total sum of square ratio and ecophysiological interpretability. The first step of clustering was applied on the matrix of scaled abiotic stress index, to identify groups of environments with similar abiotic stress patterns, referred to as environment-types (e.g. see Chenu et al., 2013 for water-deficit patterns). For the sunflower crop, this method was also used in previous studies about environmental characterization (Mangin et al., 2017; Gosseau et al., 2019). The second step of clustering was applied on the frequency of environment types per location, to identify groups of geographical locations with a similar frequency of environment types, independently of climatic variability, referred as agricultural zones (Beillouin et al., 2018).

\section{Baseline and optimization for cultivar deployment strategies.}

Here, our aim was to evaluate the impact of different cultivar deployment strategies on the distribution of grain yield across the population of cropping conditions. For that, we compared baseline with optimized deployment strategies (Table 3).

Two baseline deployment strategies were defined: random, a random choice of cultivar per cropping condition, and reference, based on surveyed cultivar acreage data. The random strategy was only used as a control and the more realistic reference strategy was the one used as a reference for the comparison with optimized strategies. We defined the reference strategy to represent the current cultivar recommendations and farmers' choices. In this strategy, we assumed that the best cultivars were those that had a major commercial success. This list was obtained by selecting $s$ distinct cultivars among the five most-grown cultivars (based on the actual sown area) and for each of the last five years of the study (2009-2013). The reference yield $\left(Y_{0}\right)$ for each cropping condition under this strategy was the average of this cultivar list, i.e. $Y_{0}=\frac{1}{s} \sum_{g=1}^{s} Y$, with $Y$, simulated grain yield, and $g$, genotypes from the cultivated list.

We defined four optimization strategies to recommended cultivars, ranging from a global adaptation strategy to a local one. The resolution of strategies differed by the number of decisions (cultivar choice) made according to the level of knowledge about the cropping conditions:

(1) global, one choice for all the population of environments;

(2) zone, one choice per agricultural zone (4 choices, see the previous section);

(3) farm, one choice per farm location (1075 choices);

(4) farm_year, one choice per farm:year combination (20566 choices).

Using the zone strategy as an illustration, the optimization algorithm first computes the mean values by cultivars for each agricultural zones (Z1, Z2, Z3, Z4), and the best cultivar is then selected for each zone, thus providing a list of optimized choices (4 cultivars, potentially distinct). This list is then used to obtain the optimized yield $\left(Y_{m}\right)$ distribution, by filtering all simulated cultivar $\times$ environments on optimal cultivar choices. The relative yield gain distribution was computed as $\frac{\left(Y_{0}-Y_{m}\right)}{Y_{0}}$. The performance of optimization strategies was estimated by computing the median value of the relative yield gain distribution. The distance between strategies was computed with the rooted-mean-squared differences between yield gain distributions. We evaluated yield stability in a conservative way, focusing on the less profitable outcomes by computing the mean of yield values below the 0.1 quantile value (expected shortfall, Acerbi 
bioRxiv preprint doi: https://doi.org/10.1101/2020.09.21.306076; this version posted September 22, 2020. The copyright holder for this preprint (which was not certified by peer review) is the author/funder, who has granted bioRxiv a license to display the preprint in perpetuity. It is made available under aCC-BY 4.0 International license.

and Tasche, 2002) of the yield gain distribution. The Expected Shortfall was computed for the yield distribution at the population of environment level and at the farm level, over the sampled years.

To avoid using all the data to select and evaluate the performance of strategies, we used a k-fold crossvalidation resampling strategy (with folds corresponding to the year factor) to select optimal cultivars on a partition of the data (all years minus one) and estimate the performance of these choices on the other partition (one year).

\section{Software and data analysis}

All data processing, statistical analysis and visualization were performed with the R software version 4.0.2 (R Core Team, 2018) with additional R packages dplyr (data processing, Wickham et al., 2018), ggplot2 (visualization, Wickham, 2016), rsample (resampling, Kuhn et al., 2019), and knitr (reporting, Xie, 2015). Both Factor Analysis For Mixed Data (FAMD) and Hierarchical Cluster Analysis (HCA) were performed with the FactoMineR R package (Lê et al., 2008). The source code for the SUNFLO simulation model is available on INRA software repository [https://forgemia.inra.fr/record/sunflo.git]. The INRA VLE-RECORD software environment (Quesnel et al., 2009; Bergez et al., 2013) was used as simulation platform.

\section{Results}

\section{Cropping conditions for the sunflower crop in France}

The surveyed farms were globally matching the main regions of sunflower production (Figure 2), with sampled regions (i.e. containing sampling points) representing over $95 \%$ of the total cumulated acreage (14.9 Mha over 1994-2013).

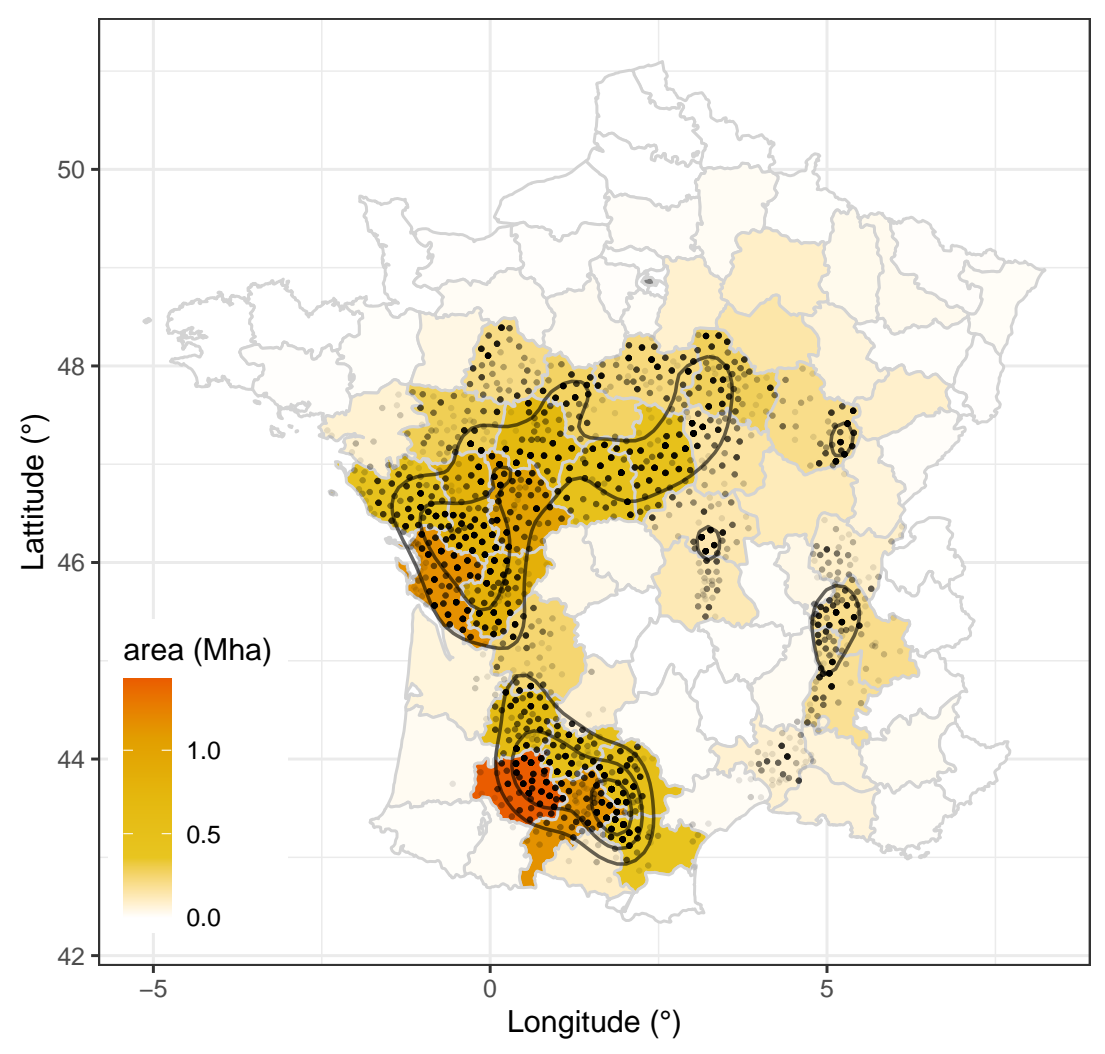

Figure 2. Map of sampled locations in the sunflower farm-level surveys. Points are the location of the 1077 unique farms sampled over 11 years (source: Terres Inovia surveys) 
with contour curves approximating the point density. Colors indicate the cumulated cropped area (Mha) on each French sub-regions (départements) for sampled years (1994-2013).

The classification analysis on management practices resulted in 8 clusters (labeled from M1 to M8 in Table 2) common to to the 11 years and the five regions of survey. Clusters were roughly balanced with average proportions between 8 and $15 \%$ of farmers. Among the 14 variables of the survey, the amount and type (organic/mineral) of nitrogen fertilization, fungicide use, and the precocity of cultivars were the main discriminative variables acting on clusters.

\begin{tabular}{|c|c|c|c|c|c|c|c|c|}
\hline group & label & $\mathrm{p}$ & sowing & density & nitrogen & boron & fungicide & precocity \\
\hline M2 & Early cultivar use & 14 & $15 / 04$ & 6 & 46 & 31 & 1 & 89 \\
\hline M4 & Early sowings, boron & 8 & $05 / 04$ & 6 & 50 & 85 & 36 & 80 \\
\hline M5 & Very late sowings, very early cultivars & 12 & $10 / 05$ & 6 & 38 & 13 & 5 & 66 \\
\hline M6 & Late cultivars & 15 & $15 / 04$ & 5 & 53 & 13 & 7 & 9 \\
\hline
\end{tabular}

Table 2. Classification of management practices for sunflower in France. Eight management types (named M1-M8) resulted from the cluster analysis of agricultural survey results (14 management-related variables, 11k observations), with their proportion indicated in percent $(p)$. Six variables were used to characterize the management type: sowing date (dd $/ \mathrm{mm}$ ), crop density (plants.m ${ }^{-2}$ ), mineral nitrogen fertilization $\left(\mathrm{kg} \cdot \mathrm{ha}^{-1}\right.$ ), frequency of boron application (\%), frequency of fungicide application (\%) and frequency of early cultivar use (\%). Label was assigned a posteriori, based on the interpretation of those six variables.

M1 management type could be considered as low input (lowest nitrogen fertilization, low fungicide use). On the opposite, M8 type could be considered as high input management: farmers systematically use a fungicide with high nitrogen fertilization and frequent boron application. Other management modalities were less discriminated by input levels and were differing mostly by the crop sowing dates (early implantation for M4 or very late for M5), and cultivar precocity (e.g. early cultivar to compensate for late implantation in M5).

Regarding the cultivated genetic diversity, we observed a strong decrease in the cumulated proportion of area for the five most sown cultivars, going from $47 \%$ to $18 \%$ (rate was $-2.5 \%$ per year, $\mathrm{p}=1.2 \mathrm{e}-7$, $\left.\mathrm{R}^{2}=0.89\right)$.

\section{Environmental characterization}

\section{Climatic and soil variability}

Globally, a large proportion of the sunflower cropping area is exposed to climatic water deficit, particularly in the South-West and West regions (Figures 2 and $3 \mathrm{~A}$ ).

For the considered climatic conditions (20560 stations x year population), weather records during the cropping season (Figure 3B) indicated that the mean sum of rainfall was $319 \pm 94 \mathrm{~mm}$, ranging from $80 \mathrm{~mm}$ to $993 \mathrm{~mm}$. Mean temperature was $17.9{ }^{\circ} \mathrm{C}$, ranging from $9.9{ }^{\circ} \mathrm{C}$ to $23.8{ }^{\circ} \mathrm{C}$. In this population of environments, $1.6 \%$ corresponds to semi-arid conditions (aridity index $\in] 0.2 ; 0.5]$ ) and $8.6 \%$ to dry sub-humid (aridity index $\in] 0.5 ; 0.65]$ ), according to Middleton et al. (1997) boundaries for dryland classification. Mean soil water capacity in the population of environments was $141 \mathrm{~mm}$, ranging from 38 $\mathrm{mm}$ to $350 \mathrm{~mm}$ (sd of $51 \mathrm{~mm}$ ) 
A

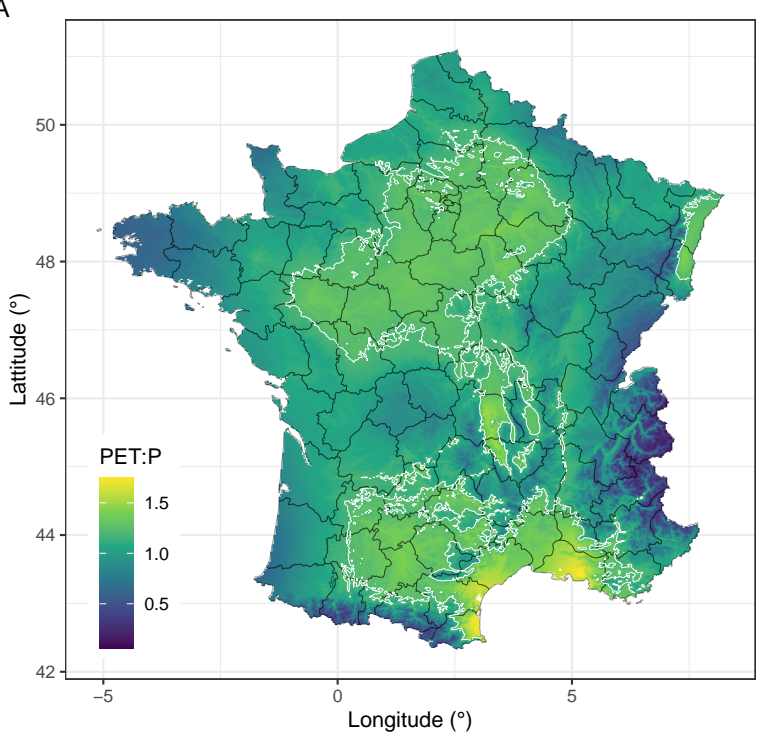

B

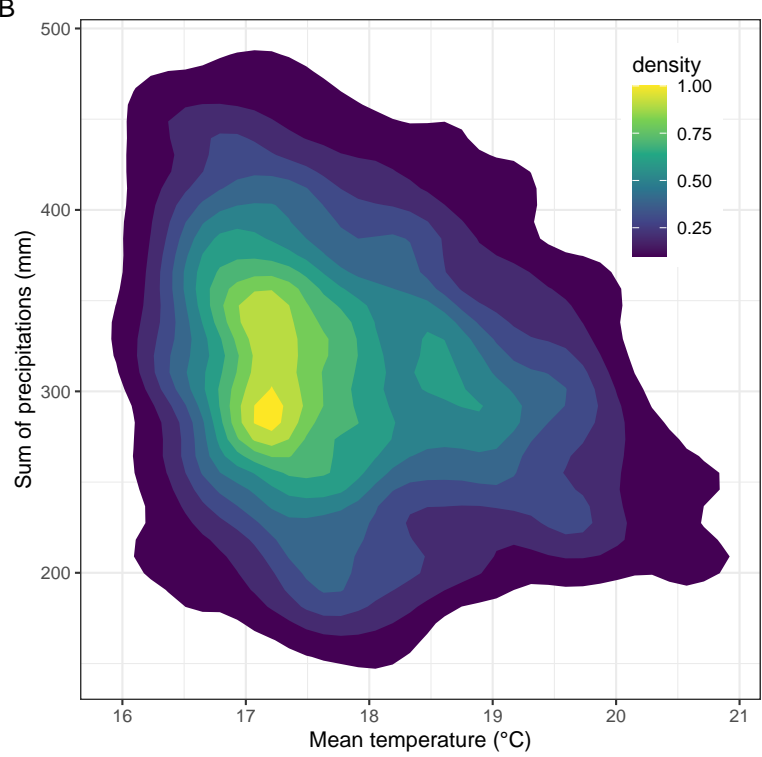

Figure 3. Climatic variability in the sampled cropping conditions. The left panel (A) displays a map of potential evapotranspiration to precipitation ratio (1 / aridity index, data from Zomer et al. (2008)). The white contour line corresponds to a PET:P ratio of 1.2, indicating geographical locations prone to water deficit. The right panel (B) shows climatic variability in the sampled gridded points (1028) over 20 years $(n=20560)$. Color is the $2 \mathrm{D}$ density estimate of the sum of precipitations as a function of the mean temperature for the population of environments. Mean and sum were computed between average sowing and harvest dates (April 15th to September 15th).

\section{Simulated abiotic variables allowed to define coherent environment types}

Figure 4 displays the variability of the simulated abiotic stressors as a function of environment type resulting from the clustering of the population of environments. Cutting the dendrogram to four groups gave a ratio between:total sum of square of $63 \%$ and allowed a sensible interpretation of stress patterns. Stress patterns were contrasted between groups, allowing to comment and name environment types (left to right in Figure 3) based on their distributions. The first group (optimal) was characterized by comparatively low mean stress levels corresponding to near-optimal cropping conditions. The second group ( cold) displayed a high level of cold stress, while the other stresses were at a very low level. The third group (heat and drought), was the only group with an important level of heat stress which was associated to moderate level of water deficit. The fourth group (drought and nitrogen) was characterized by unfavorable cropping conditions, with the strongest level of water deficit associated with nitrogen deficit. 


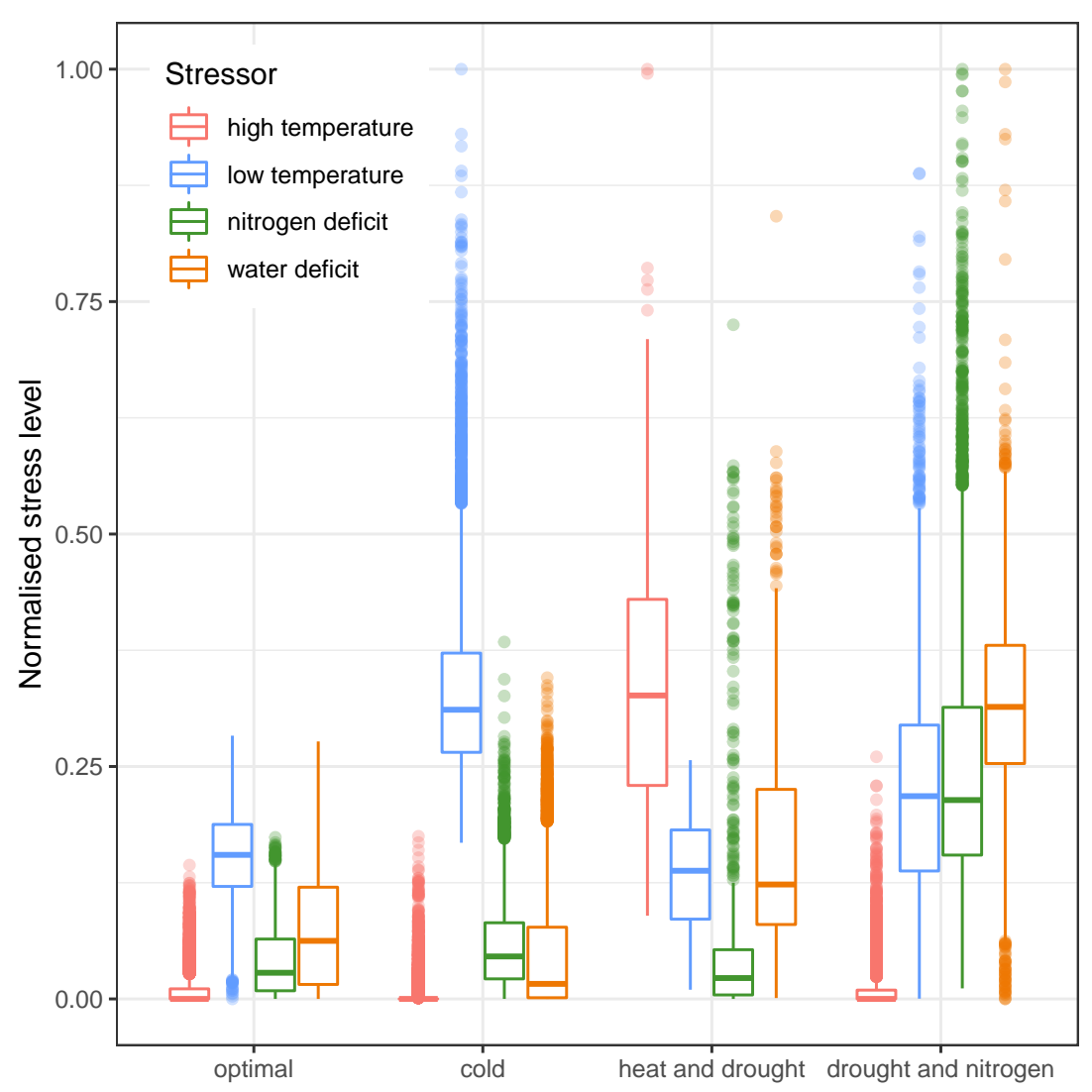

Figure 4. Distribution of abiotic stress levels as a function of defined environment types. Simulation was used to characterize the seasonal abiotic stress patterns at the crop level. Each environment was characterized by a vector of four abiotic indices, i.e. stressors integrated over the cropping season (high and low temperatures, nitrogen, and water deficit impact on crop photosynthesis). Hierarchical clustering was used to group abiotic patterns into four environment types, a posteriori named after the observed stress pattern. Values of abiotic stressors were rescaled (unity-based normalization) to allow comparisons between stressors.

\section{Temporal and spatial distributions of environment types are highly variable.}

The first cluster analysis allowed to assign a distinct type of environment to each location for each year (1075 locations $\times 20$ years, 20566 cropping environments). To better understand how these environment types were related to actual cropping conditions, we displayed the evolution of the proportion of each environment type as a function of time (Figure 5A) and the succession of environment types for each geographical location through years (Figure 5, panels C-F). At the national scale, cold and optimal environment types were the most frequent (average frequency of $51 \%$ and $28 \%$ respectively), followed by drought and nitrogen type (17\%). The frequency of occurrence of environment types was varying strongly with time, with some peculiar years such as 2003 (very high proportion of heat and drought type), 2007 and 2011 (high cumulated proportion of environment types with low water deficit), and 2012 (the highest proportion of unfavorable drought and nitrogen environment type). From a geographical point of view (Figure 5, panels C-F), the location of optimal environment types matched the area with the most sunflower acreage (South-West France). In contrast, drought and nitrogen environments were not specifically bound to climate and could be located anywhere in the cropping area (e.g. panel F), with however some recurring locations (South-East). Even if the frequency of environment types could be related to national yield for specific years (low national yield in 2003 associated with high-temperature stress and record years in 2007 and 2011), we did not find a strong relationship between the frequency of environment types and the national yield (Figure 5B). 

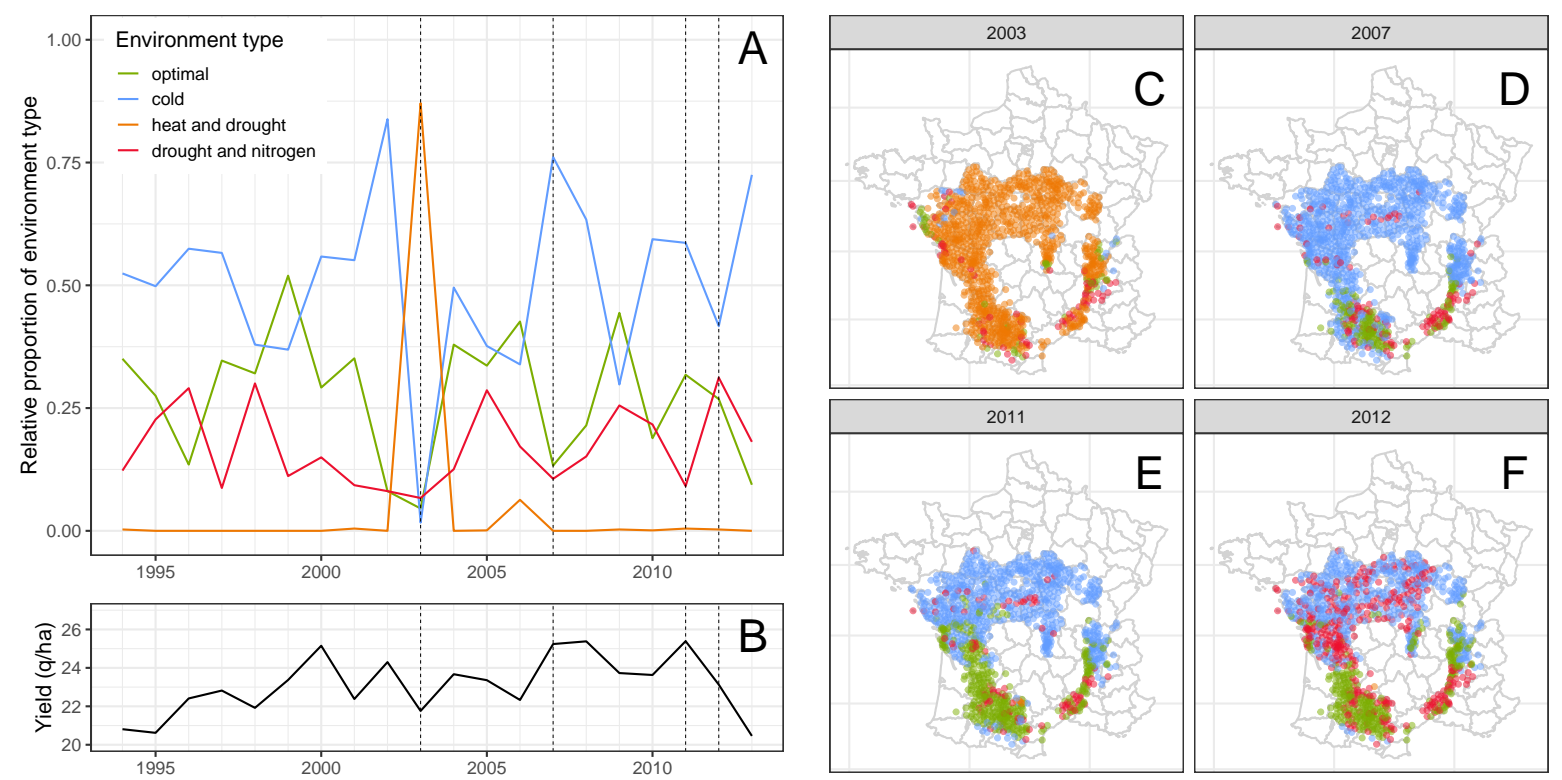

Figure 5. Temporal and spatial distribution of environment types. Panel A displays the evolution of the relative proportion of environment types over 20 years. For reference, panel B is the national sunflower yield. The right panels (C-F) display the spatial distribution of environment types for each individual cropping condition, for a subset of four contrasted years.

The second cluster analysis allowed to group locations with a similar frequency of occurrence of environment types, i.e. locations with predictable abiotic stress patterns. We found that using four groups in the cluster analysis (between:total sum of squares of $86.9 \%$ ) yielded contrasted agricultural zones with balanced proportions: from locations with consistently optimal environment types (South-West, Figure 6, Z2) to consistently drought and nitrogen deficit environment types (West, South-East, Figure 6, Z3). Still, about $30 \%$ of the locations were characterized by an unstable pattern of environment types within the years (labeled with Z1, Figure 6).

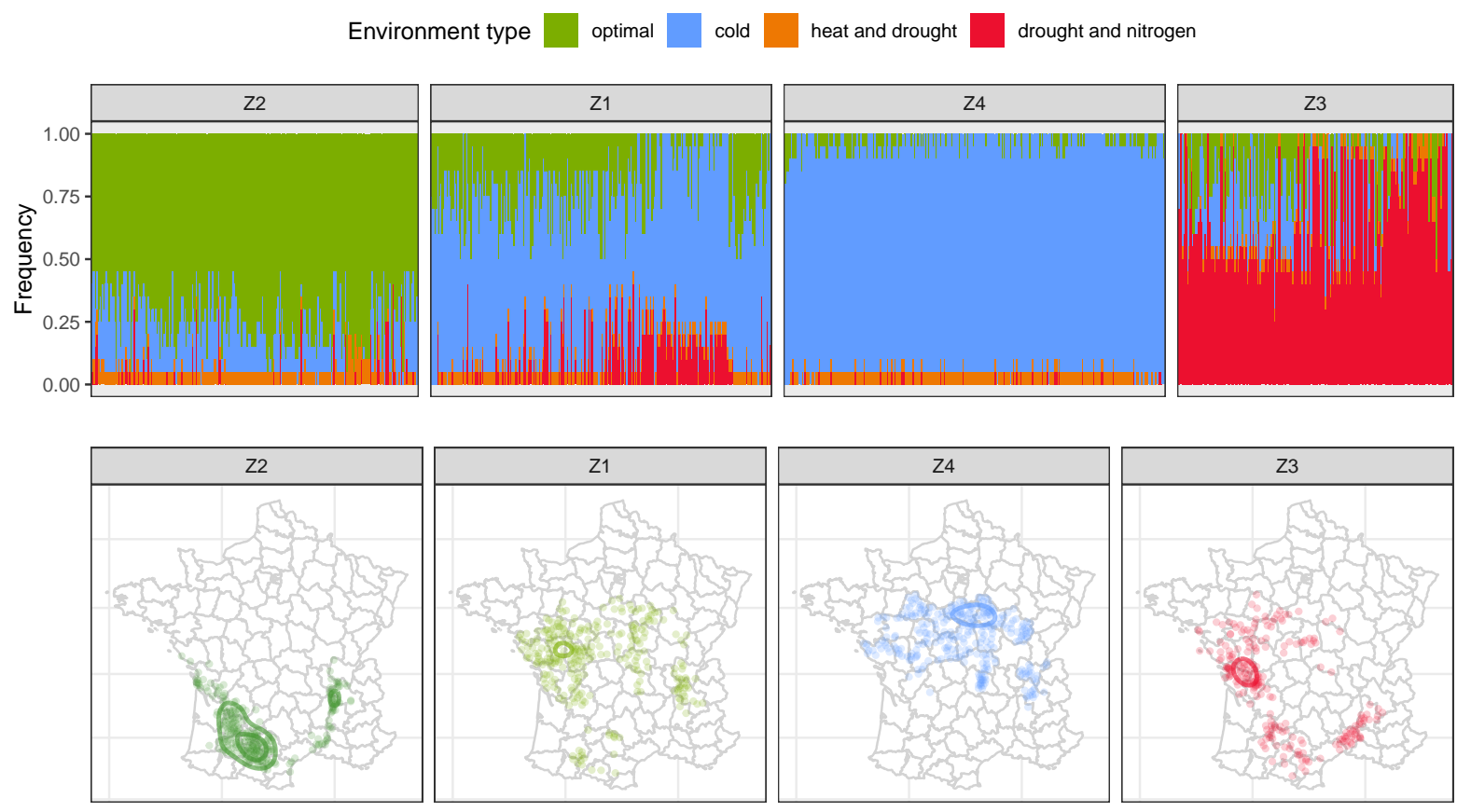

Figure 6. Identification of agricultural zones with a similar frequency of occurrence of environment types. Upper panels represent the frequency of environment types over 20 years (using stacked bars) for each farming location (ordered by increasing longitude). 
Hierarchical clustering was applied to the frequency of environment types per location, in order to identify groups of locations with a similar frequency of environment types, referred to as agricultural zones (Z1-Z4). In lower panels, the identified agricultural zones are mapped to visualize which geographical positions are sharing common and predictable abiotic stress patterns over the years.

\section{Optimization of cultivar choice}

Using the most frequently sown cultivars in France during the studied period (2009-2013) as a baseline to represent the actual deployment strategy (Figure 7, reference strategy), we showed that it was a much better strategy than randomly choosing a cultivar (among the 38 studied and available for sale) for each environment, where yield expectation was lowered by $5.7 \%$ (Table 3 ).

Figure 7 shows that the grain yield distribution was shifted towards higher yields when changing the deployment strategy from the reference to optimized cultivar choices, whether it was by choosing a single cultivar across all the population of environments or fine-tuning cultivar choice according to yearly cropping conditions on the farm. While the difference among yield distributions was clearly visible between the reference and optimized strategies, differences within optimized strategies were more tenuous and occurred mainly for low yield levels.

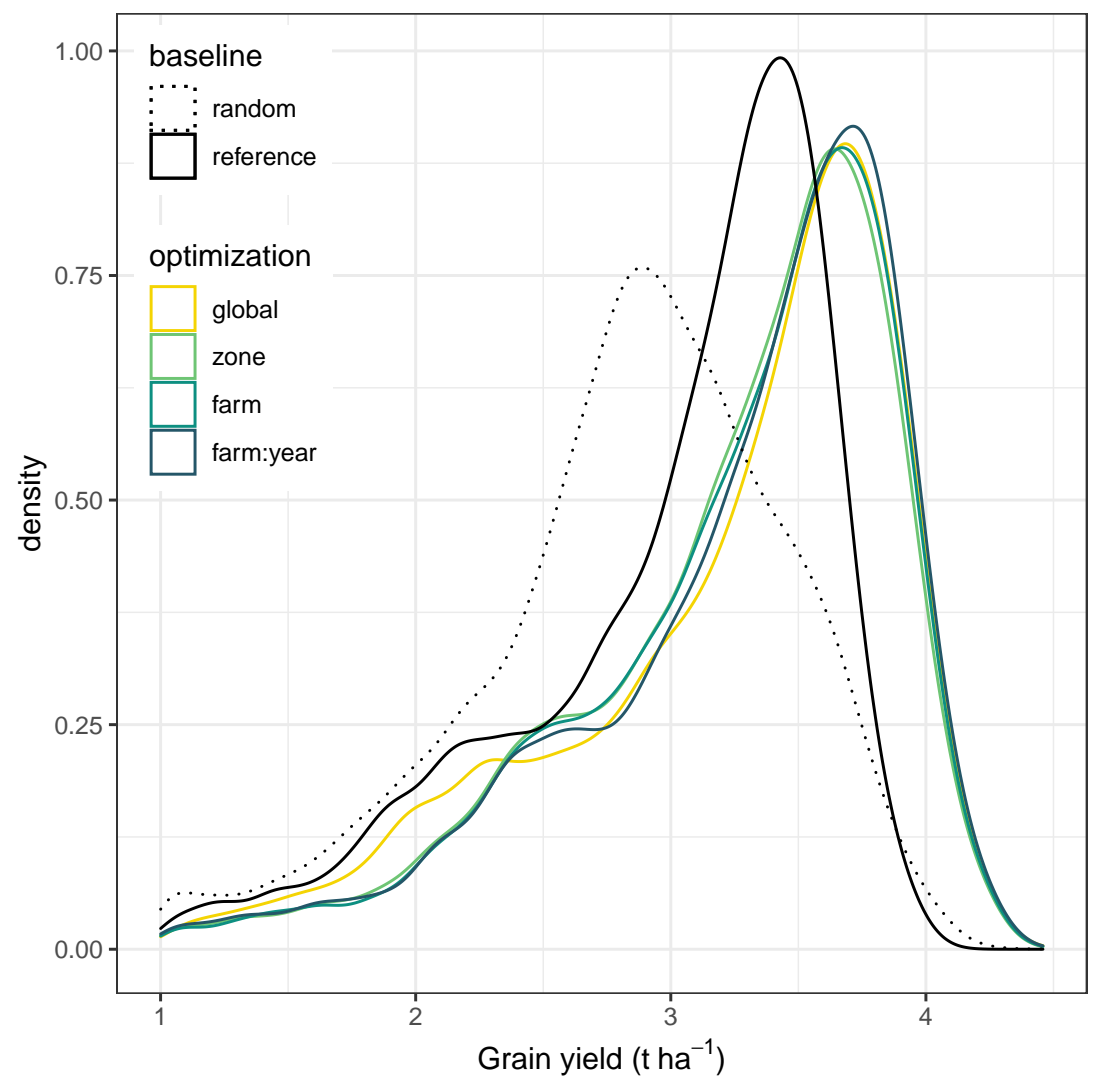

Figure 7. Impact of different cultivar deployment strategies on the distribution of grain yield across the population of cropping conditions. Two baseline deployment strategies are presented: random, a random choice of cultivar per farm $\times$ year combination (20566 choices), and reference, the mean of the most frequently sown cultivars during the studied period. The optimized deployment strategies differed by the number of cultivar choices made across the population of cropping conditions: global, one decision for all conditions; zone, one decision per agricultural zone (4 choices); farm, one decision per farm (1075 choices) and farm:year, one decision per farm $\times$ year combination (20566 choices).

Yield gain was defined as the relative difference between the considered strategy and reference one. Over the population of environments, the median gain ranged from $7 \%$ for the global strategy to $8.5 \%$ for the farm:year strategy (Table 3). The major improvement in overall crop performance was observed between 
the reference and global strategy, while other strategies brought additional but more substantial gains, with the greatest difference $(0.57 \%)$ between year and farm:year strategies. The expected shortfall, a risk measure focusing on the less profitable outcomes, increased more strongly than median gains with more precise deployment strategies. At the farm scale, the yield stability over the 20 sampled years was also increased by $6-9.4 \%$ when the cultivar choice was optimized.

\begin{tabular}{lrrrrrr}
\hline strategy & decision & diversity & distance & gain_tpe & es_tpe & es_farm \\
\hline random & 20566 & 37 & 3.4 & -5.7 & -5.8 & -10.2 \\
global & 1 & 1 & 2.2 & 7.0 & 4.0 & 6.1 \\
env_zone & 4 & 2 & 2.5 & 7.8 & 12.5 & 7.5 \\
farm & 1075 & 18 & 2.6 & 7.9 & 12.7 & 7.5 \\
farm_year & 20566 & 29 & 2.8 & 8.5 & 13.3 & 9.4 \\
\hline
\end{tabular}

Table 3. Summary table of the comparison between reference and tested cultivar deployment strategies. The cultivar deployment strategies (column strategy) were characterized by the number of decisions taken to adapt cultivars to the cropping conditions (decision), the number of distinct cultivars that were actually chosen (diversity), the distance between the reference and each optimized strategy (distance, in q.ha ${ }^{-1}$ ), the median value of the yield gain at the population level (gain_tpe, in \%), the expected shortfall gain at the population level (es_tpe, in \%) and at the farm level (over the 20 sampled years, es_farm, in $\%$ ). Expected shortfall is a risk measure focusing on the less profitable outcomes (here, the mean gain for the $10 \%$ worst cases).

Finally, we analyzed the yield gain distribution stratified by environment types to further understand how the deployment strategies were differing (Figure 8).

We found that moving from a single cultivar choice to specific recommendations had a stronger positive effect when applied to the less productive situations (lowest quantiles). For all environment-types, gains up to $15 \%$ can occur. However, with higher yield potential (highest quantiles), the gains allowed by specific recommendations are reduced to match those allowed by the global strategy. For the most unfavorable environment-type (drought and nitrogen, Figure 8), gains permitted by specific recommendations were higher than with a single cultivar choice, for all the yield quantiles. 


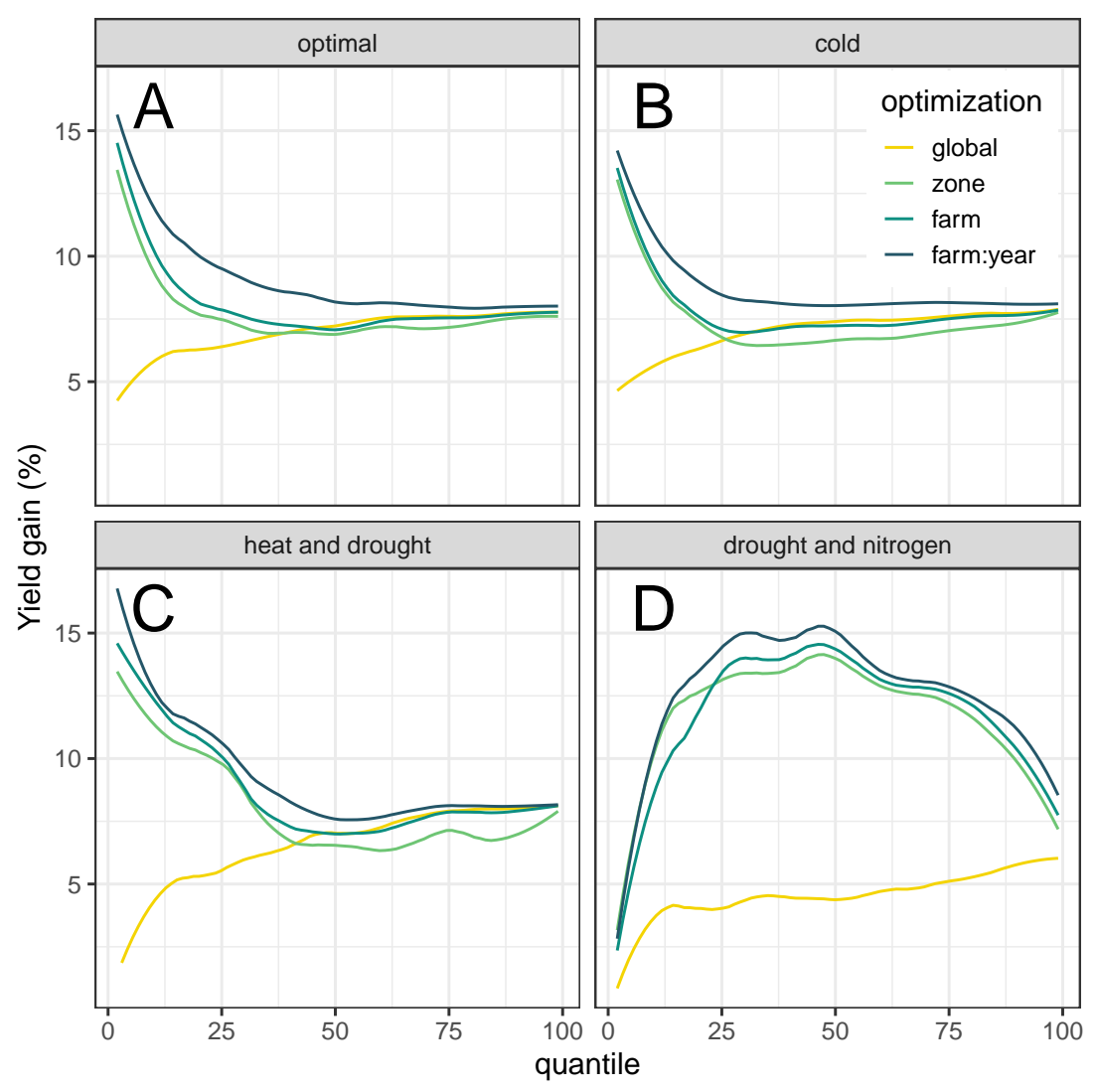

Figure 8. Gain achieved for different cultivar deployment strategies as a function of yield level. For each deployment strategy, the yield gain was computed as the relative difference between a given yield percentile for the tested strategy and the same percentile for the reference strategy. Deployment strategies involving an increased number of cultivar choices are represented with darker shades. The global yield gain distribution was stratified by environment-type and presented in different panels.

\section{Discussion}

We proposed a methodology relying on crop modeling, simulation, and optimization to predict phenotypic plasticity and to decide which cultivar to grow, given environmental conditions and predicted crop performance. This methodology was applied to the sunflower crop at a countrywide scale to assess whether targeted recommendations of cultivars could be considered as a lever to improve crop performance and stability. Working from farmer survey data, we described a large range of climate, soil, and management practices representing various cropping conditions over the country. We then used simulation to extend this initial sampling with a numerical experimental design featuring new cultivars and climates. Computational experiments showed a potential for local recommendations, with gains increasing with the knowledge of pedo-climatic conditions. But the sole pedo-climatic context was not enough to inform the cultivar choice, yield gains were increased when decisions could be made based on environment types, i.e. when diverse geographical locations and years yet experiencing similar abiotic stress patterns were grouped together.

The proposed recommendations are dependent not only on soil and climate data used to build the numerical experiment, but also on the methods and model used for the simulation and optimization step. When using two sets of climate data, differing by the downscaling method used in gridded data, we found that the results were robust to these variations. The ranking of deployment strategies was not impacted and the differences between strategies with different climate datasets was $0.45 \%$ maximum. As the crop model directly drives the phenotypic prediction, its ability to capture cultivar differences in response to environment and management drivers is essential. The algorithm of the crop model was evaluated on agricultural extension trials corresponding to a subset of the population of cropping environments 
simulated in the numerical experiment (Casadebaig et al., 2016). As reviewed by Wang et al. (2019), further progress in the functional modeling of phenotypic plasticity and therefore prediction accuracy is related to the extension of systems biology to plant and crop scale (Hammer et al., 2004; Keurentjes et al., 2011; Poorter et al., 2013). Lastly, the cultivar recommendations based on environment types depend on the methodology used to group similar environments. In this study, we summarized four abiotic drivers over the whole crop cycle, thereby integrating multiple abiotic stresses but missing phenological effects. In Australia, the clustering method used by Chenu et al. (2013) emphasized phenological effects with several sampling points over the crop cycle, by using a moving average on the simulated time serie but focused only on water deficit. In France, Beillouin et al. (2018) did not use a simulation model and acted in two steps: (1) fit a regression model (partial least square regression) to select climatic factors that best explained yield variability and (2) then use the weighted coordinates of the selected model to group environments according to these characteristics. Their approach emphasized the selection of factors that were actually impacting yield on their dataset. Another option is the clustering method used in Picheny et al. (2017b), where the distance between environments (years) was computed on the complete time serie using a non-Euclidian method (dynamic time warping). While the method was applied on raw climatic variables rather than simulated abiotic time serie it would take better account of phenology for clustering environments.

\section{Tactical agronomy}

Choosing a cultivar far before sowing is a demanding problem because there is no reliable seasonal weather forecasting for the incoming cropping season on this date. The global, zone, and farm strategies accounted for this constraint and were based on information available at sowing date, i.e. the environmental zone or the geographical location. However, the farm:year cultivar deployment strategy operates as if a perfect forecast of the incoming climate was available to choose the cultivar. While unrealistic, this strategy allowed to assess the gains expected from a perfect fit of a cultivar and an environment and revealed that this was the only strategy strongly reducing the probability of low yield outcomes at the population level (Figure 8A) and at the farm level (Table 3).

Another strong assumption of our method is that we do not account for the effect of the distribution system on the actual cultivars made available for each individual farmer. In France, farmers essentially buy seeds through agricultural cooperative groups, selling different seeds in different regions. In a way, at the farm scale, access to the full genetic diversity is thus reduced, but this distribution system also filters adapted cultivars. On this subject, Sadras and Denison (2016) highlighted how optimization approaches for decision making in crop management are constrained by various trade-offs ultimately impacting the expected gain from these approaches. They suggest that results from optimization methods are particularly useful as null hypothesis, i.e. that the divergence between actual and optimal solutions can help to identify constraints that are relevant to further explore. We could assume that spatial deployment strategies could be nevertheless promoted because national cultivar evaluation is a common feature in Europe (Van Waes, 2009). Official cultivars trials are arranged by dedicated institutes for the examination of Value for Cultivation and Use (VCU). These trials result in the production of Recommended Variety Lists and recommendations for cultivation are published either as national summaries or as regional bulletins.

We found that choosing a single cultivar was a good strategy, yielding important gains compared to the reference strategy but that were only marginally lower than more demanding strategies. We explain the relevance of this strategy because the chosen cultivar had the best adaptation to the most frequent environment-type. Favorable environments, encompassing the optimal and arguably the cold environment types, were very frequent among the population of environments (Figure 6). The cultivar responses to the range of environments were estimated by regressing cultivar yield on site mean (Finlay and Wilkinson, 1963), and the optimal cultivar for the global strategy had the best adaptation to favorable environments (i.e. the highest regression slope, which was $>1$ ) compared to other cultivars.

However, specific types of environments supported more diverse cultivar choice (Table 3), up to 29 distinct cultivars out of 37 candidates for the most precise deployment strategy. But while the diversity of recommended cultivars indeed increased, a list of 6 cultivars was sufficient to cover $99 \%$ of cases in the population of cropping environments, indicating that very specific recommendation occurs rarely. We could have expected that more recently released cultivars (after 2010) could have been more frequently recommended because of the genetic gain but the proportion of recent cultivars was 0.63 in the candidate 
list $(\mathrm{n}=37), 0.55$ in the recommended list $(\mathrm{n}=29)$, and 0.5 in the 6 most recommended list. When analyzing the phenotypic features of cultivars, we found that the harvest index value, a strong productivity-related trait (potential seed:biomass ratio), was similar in the recommended and candidate list $(\mathrm{p}=0.353)$. The fact that a recent release date and a raw productivity feature (high harvest index) are not essential for cultivars to be recommended seems to indicate that traits suited for drought-prone environments are available, yet not widespread in current commercial cultivars. But commercial hybrids are probably related because breeders use successful parents for several hybrids, reducing the apparent genetic diversity analyzed in this study. Molecular profiles of sunflower hybrids could be used in a cluster analysis to identify groups, in a similar way that we defined environmental groups.

\section{Synergy with plant breeding}

Genetic progress on sunflower was evaluated at 1.3\% per year, in the 1970-2000 period (Vear et al., 2003), with variable gain thorough years. We quantified the median gains provided by educated genotypic choices at 7 - $9 \%$ depending on the strategy used but even if this improvement does not scale with time, we could reasonably suppose that it is added to genetic progress. While the exploitation of phenotypic plasticity is often discussed with the perspective of breeding new material (Vega and Chapman, 2006; Nicotra et al., 2010; Messina et al., 2011), model-based cultivar deployment is operational on current genetic material. Moreover, cultivar deployment and breeding should act synergistically as breeding could lead to cultivars with distinctive traits that are more adapted to specific environments. This might be reflected by the steady decrease in acreage share of major cultivars observed in surveys, opening the market to more diverse cultivars.

Regardless of the way the breeding process is organized, it would be always more difficult to assess the specific adaptation of a cultivar to a particular cropping condition than to identify a more widely adapted cultivar (Vincourt and Carolo, 2018). We showed that sowing a widely adapted cultivar in all cropping conditions is an acceptable strategy, however, missing a cultivar match for an unusual cropping condition could be viewed as a wasted opportunity. In this sense, participatory plant breeding might help to produce the observations needed to support a local adaptation strategy (Vincourt and Carolo, 2018).

\section{Adaptations at the farming system scale}

The proposed cultivar deployment strategies considered a single cultivar choice for each farmer per year, because growing sole crops is the mainstream practice according to surveys. The positive effect of species or genetic diversity on ecosystem functioning (diversity-stability hypothesis) was evaluated in different systems, from mixtures of grassland species in the plot scale (e.g. Hector et al., 2010) to mixtures of crops at the farm (Paut et al., 2019) or national scale (Renard and Tilman, 2019). At the farm scale, farmers can opt for a bet-hedging strategy to minimize risk, i.e. growing cultivars having different features in distinct fields, or even by mixing cultivars in a single plot (Barot et al., 2017). In this case, adaptation without the full knowledge of the environmental conditions would allow a better crop performance because of the dampening of the abiotic stress effect at the population level (plants or plots). Among various options to transition to biodiversity-based agriculture (Duru et al., 2015), mixing cultivars probably requires a lesser adaptation for farmers and a lesser challenge for breeders.

\section{Conclusions}

Agricultural surveys were used to describe the population of environments for the sunflower crop in France. Simulation-based optimization revealed a potential for local recommendations, with gains gradually increasing with knowledge of cropping conditions, especially when distinct pedo-climatic conditions were clustered into homogeneous types of environments. At the national scale, tuning the choice of cultivar impacted crop performance the same magnitude as the effect of yearly genetic progress made by breeding. Our results suggest that optimizing the choice of cultivars according to environmental cues deserves consideration as a way to raise and stabilize crop yield at the national and farm scale. 


\section{Acknowledgements}

The authors are grateful to the students (Claire Barbet-Massin, Ewen Gery, Bertrand Haquin) and staff from INRAE (Céline Colombet, Didier Rafaillac, Colette Quinquiry), ENSAT (Michel Labarrère, Pierre Maury) and Terres Inovia (Frédéric Bardy, Philippe Christante, André Estragnat, Pascal Fauvin, Céline Motard, Jean-Pierre Palleau, Frédéric Salvi) that helped to constitute the phenotypic database. We also wish to thank the INRA RECORD team (Hélène Raynal, Eric Caselas) for modeling and simulation, and the INRA AgroClim team (Benoit Persyn, Patrick Bertuzzi) that provided gridded climate datasets. Grants were provided by the French Ministry of Agriculture (CASDAR C-2016-03 CARAVAGE) and the French Ministry of Research (ANR SUNRISE ANR-11-BTBR-0005). This work was also supported by the French National Research Agency under the Investments for the Future Program, referred as ANR-16-CONV-0004.

\section{References}

Acerbi, C., and D. Tasche. 2002. On the coherence of expected shortfall. Journal of Banking \& Finance 26(7): 1487-1503. doi: 10.1016/s0378-4266(02)00283-2.

Barot, S., V. Allard, A. Cantarel, J. Enjalbert, A. Gauffreteau, et al. 2017. Designing mixtures of varieties for multifunctional agriculture with the help of ecology. A review. Agronomy for Sustainable Development 37(2): 13.

Beillouin, D., M.-H. Jeuffroy, and A. Gauffreteau. 2018. Characterization of spatial and temporal combinations of climatic factors affecting yields: An empirical model applied to the french barley belt. Agricultural and Forest Meteorology 262: 402-411. doi: 10.1016/j.agrformet.2018.07.029.

Bergez, J.E., P. Chabrier, C. Gary, M. Jeuffroy, D. Makowski, et al. 2013. An open platform to build, evaluate and simulate integrated models of farming and agro-ecosystems. Environmental Modelling \& Software 39: 39-49. doi: 10.1016/j.envsoft.2012.03.011.

Casadebaig, P., P. Debaeke, and J. Lecoeur. 2008. Thresholds for leaf expansion and transpiration response to soil water deficit in a range of sunflower genotypes. European Journal of Agronomy 28: 646-654. doi: 10.1016/j.eja.2008.02.001.

Casadebaig, P., L. Guilioni, J. Lecoeur, A. Christophe, L. Champolivier, et al. 2011. SUNFLO, a model to simulate genotype-specific performance of the sunflower crop in contrasting environments. Agricultural and Forest Meteorology 151: 163-178. doi: 10.1016/j.agrformet.2010.09.012.

Casadebaig, P., E. Mestries, and P. Debaeke. 2016. A model-based approach to assist variety assessment in sunflower crop. European Journal of Agronomy 81: 92-105. doi: 10.1016/j.eja.2016.09.001.

Chapman, S.C., M. Cooper, and G.L. Hammer. 2002. Using crop simulation to generate genotype by environment interaction effects for sorghum in water-limited environments. Australian Journal of Agricultural Research 53(4): 379-389. doi: 10.1071/ar01070.

Chapman, S., M. Cooper, D. Podlich, and G. Hammer. 2003. Evaluating Plant Breeding Strategies by Simulating Gene Action and Dryland Environment Effects. Agronomy Journal 95(1): 99-113. doi: 10.2134/agronj2003.0099.

Chenu, K., R. Deihimfard, and S.C. Chapman. 2013. Large-scale characterization of drought pattern: A continent-wide modelling approach applied to the Australian wheatbelt-spatial and temporal trends. New Phytologist 198: 801-820. doi: 10.1111/nph.12192.

Chenu, K., J.R. Porter, P. Martre, B. Basso, S.C. Chapman, et al. 2017. Contribution of crop models to adaptation in wheat. Trends in plant science 22(6): 472-490. doi: 10.1016/j.tplants.2017.02.003.

Comstock, R. 1976. Quantitative genetics and the design of breeding programs. Proceedings of the international conference on quantitative genetics. pp. 705-718

Debaeke, P., P. Casadebaig, F. Flenet, and N. Langlade. 2017. Sunflower and climate change in europe: Crop vulnerability, adaptation, and mitigation potential. Oilseeds and fats, Crops and Lipids. doi: $10.1051 / \mathrm{ocl} / 2016052$. 
Debaeke, P., E. van Oosterom, E. Justes, L. Champolivier, A. Merrien, et al. 2012. A species-specific critical nitrogen dilution curve for sunflower (helianthus annuus l.). Field Crops Research 136: 76-84. doi: 10.1016/j.fcr.2012.07.024.

Duru, M., O. Therond, G. Martin, R. Martin-Clouaire, M.-A. Magne, et al. 2015. How to implement biodiversity-based agriculture to enhance ecosystem services: A review. Agronomy for Sustainable Development 35(4): 1259-1281. doi: 10.1007/s13593-015-0306-1.

FAO. 2020. FAO statistical database. Food and Agriculture Organization of the United Nations, Rome, Italy.

Finlay, K., and G. Wilkinson. 1963. The analysis of adaptation in a plant-breeding programme. Australian journal of agricultural research 14(6): 742-754.

Foley, J.A., R. DeFries, G.P. Asner, C. Barford, G. Bonan, et al. 2005. Global consequences of land use. Science 309(5734): 570-574. doi: 10.1126/science.1111772.

Foucteau, V., M. El Daouk, and C. Baril. 2001. Interpretation of genotype by environment interaction in two sunflower experimental networks. TAG Theoretical and Applied Genetics 102(2): 327-334. doi: $10.1007 / \mathrm{s} 001220051649$.

Gosseau, F., N. Blanchet, D. Varès, P. Burger, D. Campergue, et al. 2019. Heliaphen, an outdoor high-throughput phenotyping platform for genetic studies and crop modeling. Frontiers in Plant Science 9. doi: 10.3389/fpls.2018.01908.

Hammer, G., M. Cooper, F. Tardieu, S. Welch, B. Walsh, et al. 2006. Models for navigating biological complexity in breeding improved crop plants. Trends in Plant Science 11(12): 587-593. doi: 10.1016/j.tplants.2006.10.006.

Hammer, G.L., and D. Jordan. 2007. Scale and complexity in plant systems research: Gene-plant-crop relations. In: Spiertz, J.H.J., Struik, P.C., and Van Laar, H.H., editors. Wageningen UR Frontis Series. pp. $43-61$

Hammer, G., C. Messina, A. Wu, and M. Cooper. 2019. Biological reality and parsimony in crop modelswhy we need both in crop improvement! in silico Plants 1(1). doi: 10.1093/insilicoplants/diz010.

Hammer, G.L., T.R. Sinclair, S.C. Chapman, and E. van Oosterom. 2004. On Systems Thinking, Systems Biology, and the in Silico Plant. Plant Physiology 134(3): 909-911. doi: 10.1104/pp.103.034827.

Hector, A., Y. Hautier, P. Saner, L. Wacker, R. Bagchi, et al. 2010. General stabilizing effects of plant diversity on grassland productivity through population asynchrony and overyielding. Ecology 91(8): 2213-2220. doi: 10.1890/09-1162.1.

Hiederer, R. 2013. Mapping soil properties for europe: Spatial representation of soil database attributes. JRC, Luxembourg: Publications Office of the European Union, EUR26082EN Scientific; Technical Research series, ISSN 1831-9424; Citeseer.

Kaufman, L., and P.J. Rousseeuw. 2009. Finding groups in data: An introduction to cluster analysis. John Wiley \& Sons.

Keurentjes, J.J., G.C. Angenent, M. Dicke, V.A. Santos, J. Molenaar, et al. 2011. Redefining plant systems biology: From cell to ecosystem. Trends in plant science 16(4): 183-190. doi: 10.1016/j.tplants.2010.12.002.

Kuhn, M., F. Chow, and H. Wickham. 2019. Rsample: General resampling infrastructure.

Lecoeur, J., R. Poiré-Lassus, A. Christophe, B. Pallas, P. Casadebaig, et al. 2011. Quantifying physiological determinants of genetic variation for yield potential in sunflower. SUNFLO: a model-based analysis. Functional Plant Biology 38(3): 246-259. doi: 10.1071/fp09189.

Lê, S., J. Josse, and F. Husson. 2008. FactoMineR: An r package for multivariate analysis. Journal of Statistical Software 25(1): 1-18. doi: 10.18637/jss.v025.i01.

Li, T., A.K. Raman, M. Marcaida III, A. Kumar, O. Angeles, et al. 2013. Simulation of genotype performances across a larger number of environments for rice breeding using oryza2000. Field Crops Research. doi: 10.1016/j.fcr.2013.05.006. 
Mangin, B., P. Casadebaig, E. Cadic, N. Blanchet, M.-C. Boniface, et al. 2017. Genetic control of plasticity of oil yield for combined abiotic stresses using a joint approach of crop modeling and genome-wide association. Plant, Cell and Environment. doi: 10.1111/pce.12961.

Messina, C., K. Boote, C. Loffler, J. Jones, and C. Vallejos. 2006. Model-assisted genetic improvement of crops. Working with Dynamic Crop Models: Evaluation, Analysis, Parameterization, and Applications: 309-335.

Messina, C.D., D. Podlich, Z. Dong, M. Samples, and M. Cooper. 2011. Yield-trait performance landscapes: From theory to application in breeding maize for drought tolerance. Journal of Experimental Botany 62(3): 855-868. doi: 10.1093/jxb/erq329.

Middleton, N., D. Thomas, and others. 1997. World atlas of desertification. Arnold, Hodder Headline, PLC.

Nicotra, A.B., O.K. Atkin, S.P. Bonser, A.M. Davidson, E.J. Finnegan, et al. 2010. Plant phenotypic plasticity in a changing climate. Trends in plant science 15(12): 684-692. doi: 10.1016/j.tplants.2010.09.008.

Pagès, J. 2004. Analyse factorielle de données mixtes. Revue de statistique appliquée 52(4): 93-111.

Paleari, L., G. Cappelli, S. Bregaglio, M. Acutis, M. Donatelli, et al. 2015. District specific, in silico evaluation of rice ideotypes improved for resistance/tolerance traits to biotic and abiotic stressors under climate change scenarios. Climatic Change: 1-15. doi: 10.1007/s10584-015-1457-4.

Paut, R., R. Sabatier, and M. Tchamitchian. 2019. Reducing risk through crop diversification: An application of portfolio theory to diversified horticultural systems. Agricultural Systems 168: 123-130. doi: 10.1016/j.agsy.2018.11.002.

Picheny, V., P. Casadebaig, R. Trépos, R. Faivre, D. Da Silva, et al. 2017a. Using numerical plant models and phenotypic correlation space to design achievable ideotypes. Plant, Cell \& Environment. doi: $10.1111 /$ pce. 13001 .

Picheny, V., R. Trépos, and P. Casadebaig. 2017b. Optimization of black-box models with uncertain climatic inputs - application to sunflower ideotype design (Y. Shi, editor). PLoS ONE 12(5): e0176815. doi: 10.1371/journal.pone.0176815.

Poorter, H., N. Anten, and L.F.M. Marcelis. 2013. Physiological mechanisms in plant growth models: Do we need a supra-cellular systems biology approach? Plant, Cell \& Environment.

Quesnel, G., R. Duboz, and É. Ramat. 2009. The Virtual Laboratory Environment - An operational framework for multi-modelling, simulation and analysis of complex dynamical systems. Simulation Modelling Practice and Theory 17: 641-653. doi: 10.1016/j.simpat.2008.11.003.

Quintana-Segui, P., P. Le Moigne, Y. Durand, E. Martin, F. Habets, et al. 2008. Analysis of near-surface atmospheric variables: Validation of the safran analysis over france. Journal of applied meteorology and climatology 47(1): 92-107. doi: 10.1175/2007jamc1636.1.

R Core Team. 2018. R: A language and environment for statistical computing. R Foundation for Statistical Computing, Vienna, Austria.

Renard, D., and D. Tilman. 2019. National food production stabilized by crop diversity. Nature. doi: 10.1038/s41586-019-1316-y.

Sadras, V.O., and R.F. Denison. 2016. Neither crop genetics nor crop management can be optimised. Field Crops Research. doi: 10.1016/j.fcr.2016.01.015.

Semenov, M.A., and P. Stratonovitch. 2013. Designing high-yielding wheat ideotypes for a changing climate. Food and Energy Security. doi: 10.1002/fes3.34.

Sinclair, T., A. Soltani, H. Marrou, M. Ghanem, and V. Vadez. 2019. Geospatial assessment for crop physiological and management improvements with examples using the simple simulation model. Crop Science 0(0): 0. doi: 10.2135/cropsci2019.02.0093.

Terres Inovia. 2017. Guide de culture tournesol. Terres OléoPro.

Tilman, D., K.G. Cassman, P.A. Matson, R. Naylor, and S. Polasky. 2002. Agricultural sustainability and intensive production practices. Nature 418: 671-677. doi: 10.1038/nature01014. 
Van Eeuwijk, F.A., D.V. Bustos-Korts, and M. Malosetti. 2016. What should students in plant breeding know about the statistical aspects of genotype $\times$ environment interactions? Crop Science 56: 2119-2140. doi: doi:10.2135/cropsci2015.06.0375.

Van Ittersum, M., and R. Rabbinge. 1997. Concepts in production ecology for analysis and quantification of agricultural input-output combinations. Field Crops Research 52(3): 197-208. doi: 10.1016/S03784290(97)00037-3.

Van Waes, J. 2009. Maize variety testing for registration on a national catalogue and the impact of new technologies. Maydica 54(2): 139.

Vear, F., H. Bony, G. Joubert, D. Tourvieille De Labrouhe, I. Pauchet, et al. 2003. 30 years of sunflower breeding in France. Oilseeds and fats, Crops and Lipids 10(1): 66-73. doi: 10.1051/ocl.2003.0066.

Vega, A.J. de la, and S.C. Chapman. 2006. Defining Sunflower Selection Strategies for a Highly Heterogeneous Target Population of Environments. Crop Science 46(1): 136-144. doi: 10.2135/cropsci2005.0170.

Vincourt, P., and P. Carolo. 2018. Alternative breeding processes: At which extent participatory breeding should modify the concept of ideotypes in plant breeding? OCL 25(6): D606. doi: 10.1051/ocl/2018061.

Voss-Fels, K.P., A. Stahl, B. Wittkop, C. Lichthardt, S. Nagler, et al. 2019. Breeding improves wheat productivity under contrasting agrochemical input levels. Nature Plants 5(7): 706-714. doi: 10.1038/s41477-019-0445-5.

Wang, E., H.E. Brown, G.J. Rebetzke, Z. Zhao, B. Zheng, et al. 2019. Improving process-based crop models to better capture genotype $\mathrm{x}$ environment $\mathrm{x}$ management interactions. Journal of Experimental Botany 70(9): 2389-2401. doi: 10.1093/jxb/erz092.

Wickham, H. 2016. Ggplot2: Elegant graphics for data analysis. Springer-Verlag New York.

Wickham, H., R. François, L. Henry, and K. Müller. 2018. Dplyr: A grammar of data manipulation.

Xie, Y. 2015. Dynamic documents with R and knitr. 2nd ed. Chapman; Hall/CRC, Boca Raton, Florida.

Xu, Y. 2016. Envirotyping for deciphering environmental impacts on crop plants. Theoretical and Applied Genetics 129(4): 653-673. doi: 10.1007/s00122-016-2691-5.

Zomer, R.J., A. Trabucco, D.A. Bossio, and L.V. Verchot. 2008. Climate change mitigation: A spatial analysis of global land suitability for clean development mechanism afforestation and reforestation. Agriculture, Ecosystems \& Environment 126(1): 67-80. 